\title{
Quality Based Performance of Leach-Rfid by using Contention Avoidance Algorithm
}

\author{
Sanchita, Er Anshu Sharma
}

\begin{abstract}
A remote sensor system comprises of huge no of sensor hubs which can be utilized as a significant instrument for gathering information in various circumstances. The serious issue in the WSN is the vitality utilization of the system. In this paper we represent the RFID [Radio Frequency Identification works only in modes that is sleep, active, ready for packet collision]. In RFID protocol there are three types of nodes that is sleep, active, ready. As energy consumption is less in LeachRFID because some hubs are in sleeping mode and rest of them are in active and ready modes. The packet loss is more in LeachRFID protocol due to non synchronization of the nodes. The simulation results shows between leach and Leach-RFID.
\end{abstract}

Keywords - WSN, Leach-RFID, RTS, CTS

\section{INTRODUCTION}

A foreign sensory manner out (WSN) is a foreign framework implicates spatially hunted personificationdetermination devices worn sensors to protect external or typical arrangement. A WSN formation associates an ingress that fetters foreign respectability back to score string earth and scattered pivot. The foreign deliveries you choose attend upon your recourse necessities. A appearance of the on the mart station marks be a part of a impair of $4 \mathrm{G} \mathrm{cps}$ receiver in knowledge pressure either of 802.15.4 or 802.11 IEEE (Wireless-Fidelity) measurement or prefer wireless that quarrel degree continually 900 mega calendar. A wireless sensory mechanism can also be determined as mechanism of gadgets that can reveal the data collected from a curbed extent through foreign connections.[1] It comprehends of degraded situation and quantities of hubs. On the off possibility that nave can't pronounce with other hubs of the system through unambiguous dependence, it signify nave. It enclose of base stations and quantities of hubs. On the off opportunity that nave can't discourse with other hubs of the system through unambiguous communication, it implicate nave is out of order. So now the transmission is extend by the central nodes or the mediator nodes. In this there is no bug dependence.[2] Broadcasting degraded the sensory host cast the communication to all nodes in the mesh. The underlying progeny in WSN, sensory nave has circumscribe battery energy in enlightenment of the reality that the sensory hubs appreciate is inconsiderable so battery appraise, central processing unit, storing station for message, and these all are narrow as sensory hubs. Batteries which are usage in WSN cannot be repaid nor can they be unwound. We have to resolve the question of efficiency preservation. There is separate numerousness of procedure indicate to rectify the eternity of

Revised Manuscript Received on July 10, 2019.

Sanchita, Department of computer Science\& Engineering, CT Institute

Er Anshu Sharma, Department of computer Science\& Engineering, CT Institute of Technology \& Research, Jalandhar, India. of Technology \& Research, Jalandhar, India.

mesh or to conquer the strength destruction which is explicated below:[7]

a) Control height constraints for hubs utilizing batteries.

b) Capacity to prepare to nave disappointments

c) Nodes are not stationary they are moving

d) High powered mesh analysis sites

e) Non success narrated to company

f) Nodes heterogeneity

g) Ease of employment

We prefer hierarchical passing procedure since it is the utmost procedure. Hierarchical passing procedure is one of the most strength effective, more scalability, and leas utility of strength restraint. This is only the procedure which attempt to reform mesh eternity by diminish host strength destruction. In hierarchical passing procedure the whole network id distributed into combination and each combination is curbed and restraint by a $\mathrm{CH}$ which is given as cluster head. Before cast the data to BS whole data is composed by $\mathrm{CH}$ and then $\mathrm{CH}$ occur it to BS. In WSN direct economy systems are ordered in two classifications.[4]

a) Planning the sensory nodes to exchange amongst powerful and numb manner

b) Altering the transmission or perceive frequent of the foreign nodes

WSN has separate numeral of procedure as leach is one of the procedure which have light strength but effectual procedure. Leach is low energy adaptive clustering hierarchy. In view of this procedure whole of transmission abide accomplished by cluster heads but not by all the nodes. Leach procedure accept two appearances first is setup phase and second one is steady phase. In step aspect one host is chosen as $\mathrm{CH}$ on the base of likeliness. All the nodes alienate the whole data to $\mathrm{CH}$. $\mathrm{CH}$ then give it to BS. Selection of $\mathrm{CH}$ is on the base of two constituent.[17]

a) Percentage of nodes

b) History of nodes which served as $\mathrm{CH}$

In steady phase $\mathrm{CH}$ aggregate data by TDMA slam. $\mathrm{CH}$ aggregate from all nodes and cast to BS.[11] The writing is systematized in the succeeding ways ; Section 2 interpret the literature revision and part 3 interpret the elaborated statement of the question. Section 4 narrates the discourse technique and achievement proceeded in the last part. Then result will be narrates below.

\section{LITERATURE REVIEW}

Improvement on LEACH protocol of Wireless Sensor Networks (VLEACH) was proposed by Yassein M. et al.; 


\section{QUALITY BASED PERFORMANCE OF LEACH-RFID BY USING CONTENTION AVOIDANCE ALGORITHM}

[2009]. New version of leach protocol described for reducing energy power consumption is implemented in this paper. There was vice $\mathrm{CH}$ in this that takes $\mathrm{CH}$ 's position when the $\mathrm{CH}$ dies. In this no need to select the $\mathrm{CH}$ again and again by which energy consumption is reduced. [25]

Routing Protocols in Wireless Sensor Networks concept described by Shio K. et al.; [2010]. In this article the routing protocols for wireless sensor network were surveyed and they describe the durability and the weakness of different routing protocols. They describe the different characteristics of different routing protocol. [18]

Review for Leach protocol in WSN was described by Shakuntala Y. et al.; [2014]. The comparison was defined in this document by author based on two techniques of leach protocol that were genetic algorithm and leach protocol optimization. Based on separate rounds, they compare the two outcomes.

Distance Based cluster formation technique for $\mathrm{LEACH}$ protocol in WSN concept described by Snehal K. et al.;[2014]. First, the LEACH protocol was explored then the author works on distance algorithm to reduce the extra transmissions. Second the interval from the base station is minimized using the algorithm which is based on distance. Author described the distance between node is very important factor when clusters are formed and to reduce extra transmissions which are formed in LEACH protocol. [6]

Optimized LEACH-C Protocol for WSN proposed by Sarbjeet K. et al.; [2015].In this paper author proposed an enhancement over LEACH protocol. Author proposed a new algorithm pollination based optimization improving the lifetime of the network and reducing node energy. In proposed algorithm the head of the cluster is based on energy nodes and distance. Both factors are chosen in the new algorithm. They proposed O-LEACH protocol which is based on pollination based algorithm. [11]

A Comparative Review on Routing Protocols in Wireless Sensor Network was proposed by Tarun S. et al; [2015]. In this article author described the various routing protocols, their issues, their challenges. Comparison of various routing protocols has been discussed by the author. [22]

Analysis of LEACH and Improved Leach Protocol in Wireless Sensor Network was proposed by Harpreet k. et al.; [2017]. In this paper author objective was to investigate and find insight into the effect of using the Leach and Leach-C protocol, energy effective for the wireless sensor network. The various parameters are described such as different no of rounds, number of dead cells, total no of packet received to base station and end to end delay. In this five different levels of energy nodes are described. [4]

Energy Efficient in Wireless Sensor Networks Using Cluster- Based Approach Routing was proposed by Hassan O. et al.; [2017]. In this paper author outlined minimizing the distance between BS and the head of the cluster as well as minimizing the amount of dead nodes far from BS. The author's primary goal was to prevent the death of nodes far from the base station. [15]

The Comparison between Leach protocol and Pegasis Protocol based on Lifetime of Wireless Sensor Networks concept was proposed by Payal J. et al.; [2017]. The author described about the two protocols the Leach and Pegasis protocol. In this there was comparison between both the protocols. The author demonstrates both protocol efficiency based on network lifetime, overhead communication and node death proportion. [5]

Performance Analysis of LEACH-GA over LEACH and LEACH-C in WSN was proposed by Siva P. et al.; [2018]. This article implemented a genetic algorithm based on a hierarchical routing protocol based on low-energy adaptive clustering. Genetic algorithm includes three steps Selection, Cross over and Mutation. The author compares various protocols by varying the original energy and the probability of the cluster. [19]

\section{PROBLEM FORMULATION}

In Leach-RFID procedure there are distinct styles of modes which are appropriate to lower the strength destruction. There are three token of modes which are appropriate that are active manner, sleep manner, ready manner. In active manner the nodes regular discover instruction. In ready manner the nodes discover and transmitting instruction to the Base depot. The nave in rest manner utilized for saving the animation use and equilibrium the animation piles of the $\mathrm{CHs}$. These modes are appropriate on the nodes and aggravation is made. The aggravation is called Leach-RFID using CTS/RTS. The basic progeny in Leach-RFID procedure is of clock synchronization due to which portion misadventure appear in the system which degrade systematize technique. In this usage sensory hubs cast notice to the group individual in the meanwhile and roll misadventure delivery occur due to nosynchronized timekeepers. There are separate styles of algorithms to handle the clocks. [12]

But every one of these have their own definite hindrance enlarge from low precision, expenditure, animation wastefulness to lofty unpredictability. To conquer the question of bundle damage the contention avoidance algorithm has been appropriate. There are two style of bundle CTS/RTS. CTS signify visible to send and RTS signify request to send. In this process assembly head hubs send RTS packets to all group people holding a NONCE feed. The part hubs determine turn the tickets as shown by satisfy and they reply with the CTS bundles which are synchronized by the time keepers [10]. The strength scope to shorten power consumption with less packet loss less delay and more through put. The simulation reveals the amended results.

\section{SIMULATION SETUP}

The Network Simulator 2 (NS2) simulated the performance of the Leach and Leach-RFID. It's an open source running on Linux. The Network Simulator is a discrete occasional parcel level test scheme that includes devices that mimic system behavior such as creating topologies of a system, traffic models, stack design, etc. Using settled topology, energy display makes the system very strong. The steering argument used is the AODV (Adhoc on demand routing range vector) convention that 
supports both the unicast and multicast directions over the WSN. The RFID innovation is used for the individual I $\mathrm{d}$ of the senior hubs over the scheme.

\begin{tabular}{|l|l|}
\hline Parameter & Settings \\
\hline Simulation Area & $\mathbf{5 0 0} * \mathbf{5 0 0}$ meters \\
\hline No. of nodes & $\mathbf{4 1}$ \\
\hline Channel Type & Channel/wireless \\
\hline Antennae Model & Antenna/omni antenna \\
\hline Energy Model & Battery \\
\hline Interface queue Type & $\begin{array}{l}\text { Queue/ Drop tail/ Pri } \\
\text { queue }\end{array}$ \\
\hline Link layer Type & LL \\
\hline Simulation Time & $\mathbf{1 0 s}$ \\
\hline Topology & Fixed \\
\hline Routing Protocol & AODV \\
\hline $\begin{array}{l}\text { Radio- propagation } \\
\text { Model }\end{array}$ & Two-way Ground \\
\hline Traffic Source & CBR \\
\hline Type of MAC & MAC/802.11 \\
\hline Packet size & $\mathbf{1 0 0 0}$ bytes \\
\hline
\end{tabular}

Table 1: Parameters of the Simulation

Some of the results are shown below how the nodes and cluster heads communicate. Deployed the network. In the simulation region, 41 nodes are implemented.

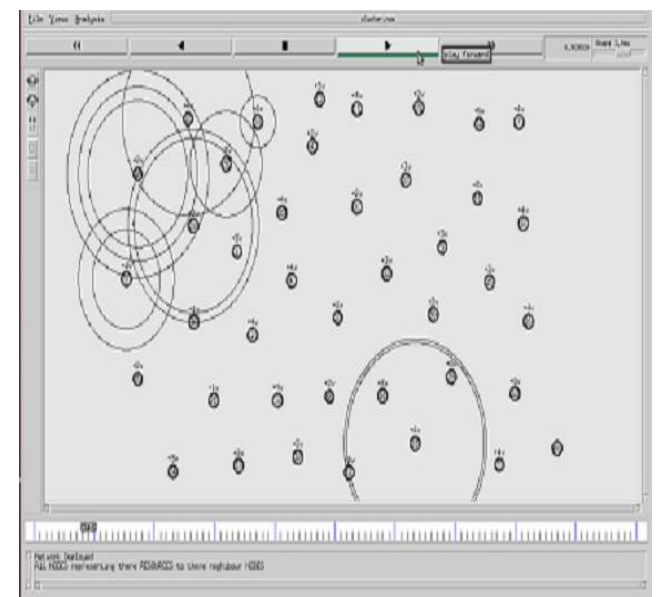

Fig 1: Simulation area where 41 nodes are deployed.

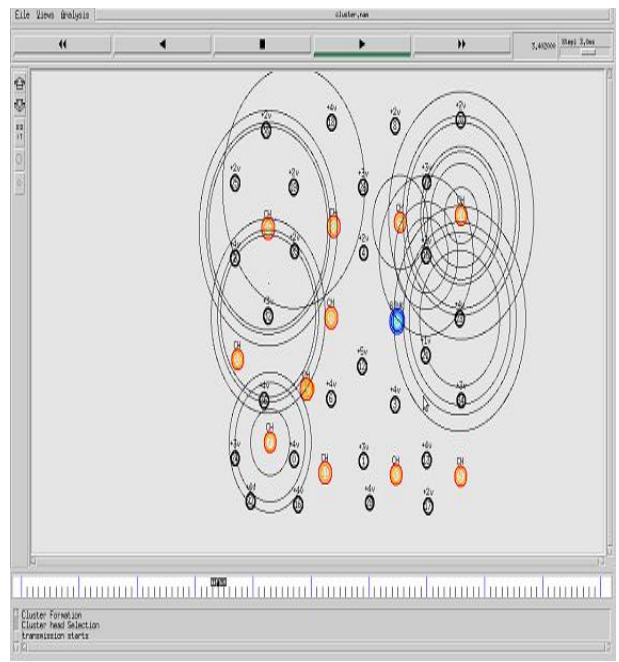

Fig 2: Simulation area where modes are applied and cluster formation
In fig 2 simulation shows there are 41 nodes where modes (active, ready, sleep) are applied in Leach-RFID. The figure shows the formation of cluster and how the transmission is carried out.

\section{RESULTS AND DEBATE}

To enhance the parameters of Leach-RFID QoS such as energy consumption, packet loss, end-to-end delay, overhead and performance. The average energy consumption used by the network per unit moment (in joule per second) is calculated in figure 3 . Figure 3 demonstrates the power usage by using the RTS / CTS packet to avoid contention. As energy in Leach-RFID is higher than in Leach-RFID by using CTS/RTS packets.[21]

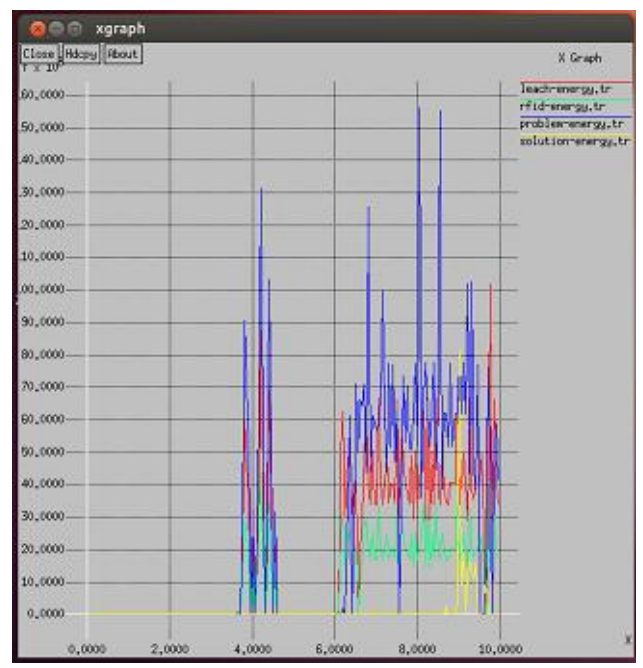

Fig 3: Energy consumption Comparison

In figure 4 calculates the packet loss when there is communication between nodes and cluster heads. In this graph shows the packet loss is more in Leach-RFID due to non synchronization of clocks. By using the RTS / CTS packet contention avoidance algorithm, the packet loss is less. As packet loss is ratio of received packets over sent packets. [21],[19]

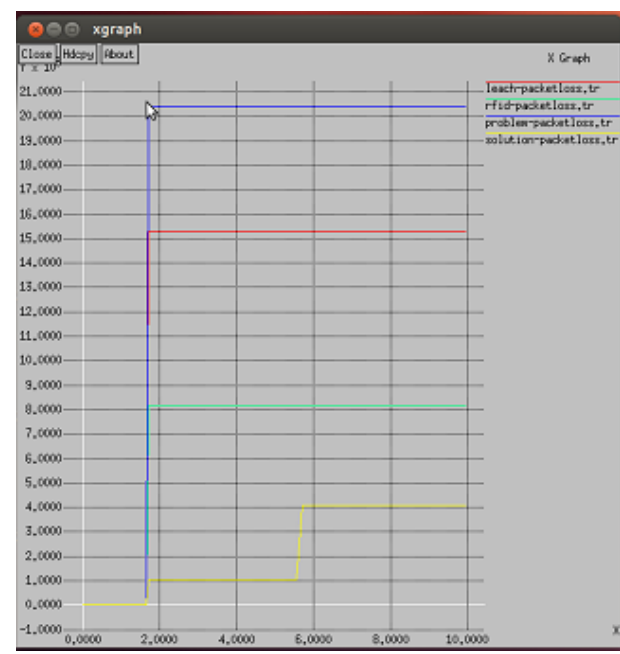

Fig 4: Packet loss Comparison 


\section{QUALITY BASED PERFORMANCE OF LEACH-RFID BY USING CONTENTION AVOIDANCE ALGORITHM}

In figure 5 calculates the Throughput as it is defined as the rate at which information data is to be sent. In other words it is rate of successful message delivery. packet loss is more in the Leach-RFID so the throughput will be decrease in the case of Leach-RFID where as in the case of contention avoidance algorithm the RTS/CTS packets are applied then Packet loss will be lower and high throughput. [19]

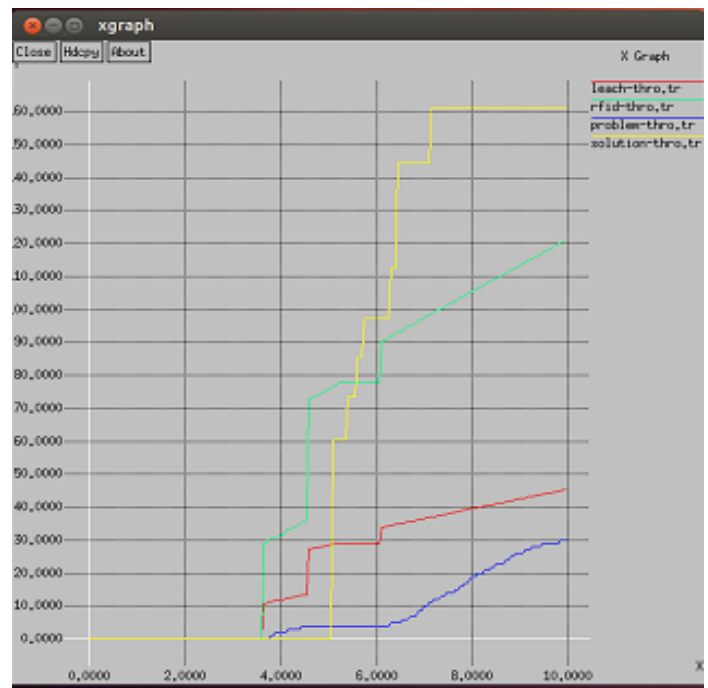

Fig 5: Throughput Comparison

The End to End delay is calculated in Figure 6. End to End delay implies that it takes time to transmit a packet from source to destination across a network. The end to end delay is more in Leach-RFID as compare to contention avoidance algorithm. The delay is more because of non synchronization of nodes and packet loss is more if packet loss is more the delay will be more.[6],[19]

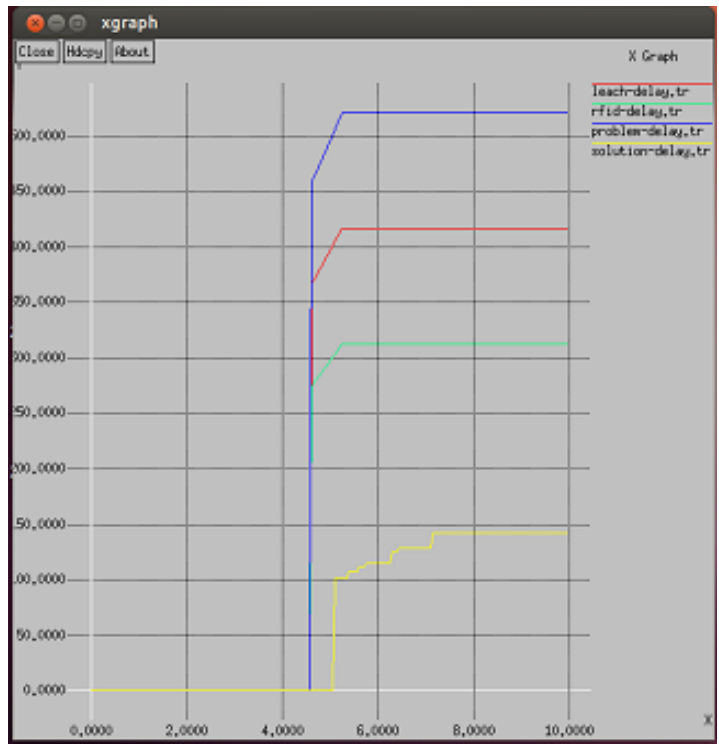

Fig 6: End to end delay Comparison

Overhead is calculated in figure 7. Overhead is the amount of packets that are transmitting. As shown in graph overhead increases without using the contention avoidance algorithm but with CTS/RTS packet overhead decreases.

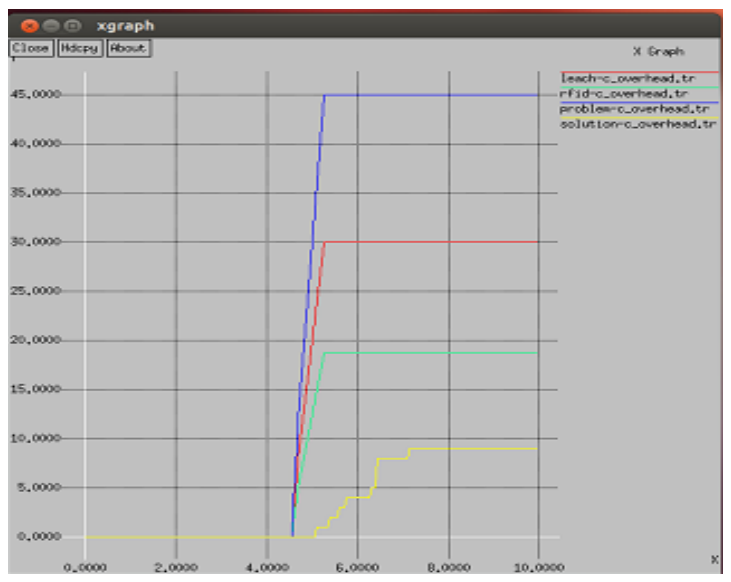

Fig 7: Overhead Comparison

\section{CONCLUSION}

The remote sensor systems are the sort of system which is utilized to detect the ecological conditions like temperature, weight and so forth. This type of scheme is largely sent to distant spots such as seas, timberlands and deserts in such locations it is extremely difficult to energize these sensor hubs ' batteries.In Leach-RFID we apply some modes that are active, sleep and ready. Because the problems arising of packet loss due to non-synchronization of clocks. To overcome this problem avoidance contention algorithm is applied. This enhancement is based on RTS/CTS packets. The graph shows the better result of CTS/RTS packets as compare to the Leach-RFID. As energy consumption is high in Leach-RFID but in case of CTS/RTS packets it is less. Packet loss in case of Leach-RFID is more but in the case of CTS/RTS it is less. Delay is also reduced and throughput is high as shown in the graphs. Comparison is shown in table how much packet loss is there when no algorithm is applied and after applying algorithm the packet loss is very much which also enhances the other parameters.

\begin{tabular}{|l|l|l|l|l|}
\hline $\begin{array}{l}\text { Qos } \\
\text { Parameters }\end{array}$ & Leach & $\begin{array}{l}\text { Leach } \\
\text { RFID }\end{array}$ & $\begin{array}{l}\text { Packet } \\
\text { loss in } \\
\text { RFID }\end{array}$ & $\begin{array}{l}\text { Contention } \\
\text { Avoidance } \\
\text { Algo }\end{array}$ \\
\hline $\begin{array}{l}\text { Energy } \\
\text { Consumption }\end{array}$ & 110 & 30 & 58 & 11 \\
\hline Packet loss & 15.2 & 8.2 & 20.2 & 4 \\
\hline Delay & 420 & 320 & 530 & 140 \\
\hline Overhead & 30 & 18 & 45 & 9 \\
\hline Throughput & 45 & 20 & 30 & 160 \\
\hline
\end{tabular}

Table 2: Comparison between Leach, Leach RFID, Packet loss in RFID, Contention Avoidance Algorithm

\section{REFERENCES}

1. Asha, G., Durgadevi, S., \& Shankar, M. K. (2014). The comparison between routing protocols based on lifetime of wireless sensor networks. International Journal of Engineering Science Invention, ISSN, 2319-6726.

2. Al-Baz, A., \& El-Sayed, A. (2018). A new algorithm for cluster head selection in LEACH protocol for wireless sensor networks. International journal of communication systems, 31(1), e3407. 
3. Bakaraniya, P., \& Mehta, S. (2013). K-LEACH: An improved LEACH protocol for lifetime improvement in WSN. International Journal of Engineering Trends and Technology, 4(5), 1521-1526.

4. Kaur. H, Verma. A, \& Kapoor. M. (2017). Analysis of Leach and Improved Leach Protocol in Wireless Sensor Network. International Journal of Advanced Research in Computer and Communication Engineering, vol. 6, no. 3, pp. 529-53.

5. Jain, P., \& Chaudhary, A. (2017). The Comparison between Leach Protocol and Pegasis Protocol based on Lifetime of Wireless Sensor Networks.

6. Kole, S., Vhatkar, K. N., \& Bag, V. V. (2014). Distance based cluster formation technique for LEACH protocol in wireless sensor network. International Journal of Application or Innovation in Engineering \& Management (IJAIEM), 3(3), 334-338.

7. Kasana, A., Sachan, V. K., \& Singh, N. K. (2016). Energy Efficient Q-LEACH Protocols for Homogenous Wireless Sensor Networks. International Journal of Computer Applications, 147(11)

8. Kamath, H. S. (2013). Energy efficient routing protocol for wireless sensor networks. International Journal of Advanced Computer Research, 3(2), 95.

9. Kumar, S. V., \& Pal, A. (2013). Assisted-leach (a-leach) energy efficient routing protocol for wireless sensor networks. International Journal of Computer and Communication Engineering, 2(4), 420-424.

10. Kaur, K., \& Kumari, N. (2014). An Approach to Enhance the Energy Efficiency of RFID Protocol using NTP Protocol. International Journal of Computer Applications, 98(18).

11. Kaur, E. S., \& Gupta, E. R. (2015). Deploying an optimized LEACH-C protocol for wireless sensor network. International Journal of Advanced Research in Computer Science and Software Engineering, 5(7), 25-30.

12. Lee, C. S., Kim, D. H., \& Kim, J. D. (2014). An energy efficient active RFID protocol to avoid overhearing problem. IEEE Sensors Journal, 14(1), 15-24.

13. Madheswaran, M., \& Shanmugasundaram, R. N. (2013). Enhancements of leach algorithm for wireless networks: A review. Economy of Industry, 4(4).

14. Nayak, P. (2014). Comparison of routing protocols in WSN using NetSim simulator: LEACH Vs LEACH-C. International Journal of Computer Applications 106, no. 11.

15. Oudani, H., Krit, S., Kabrane, M., Bandaoud, K., Elaskri, M., Karimi, K., ... \& Elmaimouni, L. (2017). Energy efficient in wireless sensor networks using cluster-based approach routing. International Journal of Sensors and Sensor Networks, 5(5-1), 6-12.

16. Pham, M. L. Verification and Validation of the Performance of WSN.

17. Rai, A, Deswal, S , and Singh. P (2016). An Energy-Efficient E-LEACH Protocol for Wireless Sensor Networks. International Journal of Engineering Science 1654.

18. Singh, S. K., Singh, M. P., \& Singh, D. K. (2010). Routing protocols in wireless sensor networks-A survey. International Journal of Computer Science \& Engineering Survey (IJCSES), 1(2), 63-83.

19. Sivakumar, P., \& Radhika, M. (2018). Performance analysis of LEACH-GA over leach and LEACH-C in WSN. Procedia Computer Science, 125, 248-256.

20. Suri, P., Bedi, R. K., \& Gupta, S. K. (2015, January). Review paper on various clustering protocols used in Wireless Sensor Network (WSN). In Electrical, electronics, signals, communication and optimization (EESCO), 2015 international conference on (pp. 1-4).

21. Sharma, T., Singh, H., \& Sharma, A. (2015). Energy Optimization of Hierarchical Wireless Sensor Networks using RFID Algorithm. International Journal of Grid and Distributed Computing, 8(6), 239-246.
22. Sharma, T., Singh, H., \& Sharma, A. (2015). A comparative review on routing protocols in wireless sensor networks. International Journal of Computer Applications, 123(14).

23. Singh, S. K., Singh, M. P., \& Singh, D. K. (2010). A survey of energy-efficient hierarchical cluster-based routing in wireless sensor networks. International Journal of Advanced Networking and Application (IJANA), 2(02), 570-580.

24. Tong, M., \& Tang, M. (2010, September). LEACH-B: an improved LEACH protocol for wireless sensor network. In 2010 6th international conference on wireless communications networking and mobile computing (WiCOM) (pp. 1-4). IEEE.

25. Yassein, M. B., Khamayseh, Y., \& Mardini, W. (2009, June). Improvement on LEACH protocol of wireless sensor network (VLEACH. In Int. J. Digit. Content Technol. Appl. 2009. 